\title{
TERMINOLOGIA MÉDICA
}

Simonides Bacelar

DOI - 10.5935/2236-5117.2015v52n3/4a14

\section{ADRENOCORTICOTRÓFICO OU ADRENOCORTICOTROPICO?}

Ambos os nomes constam da literatura médica e da Fisiologia, sobretudo nas nominações hormônio adrenocorticotrófico ou adrenocorticotrópico, cuja sigla é ACTH. Também se usam as denominações corticotropina ou corticotrofina em lugar dos nomes anteriores.

No entanto, a significação literal de ambos diferem, já que trophos, em grego, indica alimentação, alimento, nutrição, nutriente. Conexo com -trofia, ação de alimentar, alimento, nutrição, nutriente, formador. Com o suf. -ico, de adjetivos derivados dos substantivos, como em hipertrófico, hipertrofiado, que literalmente indicam supernutrido ou superalimentado.

Tropós, também em grego, significa conduta, modo de agir, orientação, direção ou direção específica, como no termo tropismo. Procede do verbo grego trépó, voltar, virar, dirigir, daí, trópico no sentido de volta, círculo da esfera terrestre (Houaiss, 2009; R. Galvão, Vocabulário Etimológico de Palavras Derivadas do Grego, 1994). Trata-se de polissemia, evento comum nas significações das palavras.

Tendo em vista esses achados, o nome mais adequado para denominar o hormônio em questão é h. adrenocorticotrópico, já que, procedente das células corticotrópicas do lobo anterior da hipófise (L. Rey, Dic. de Termos Téc. de Medicina ..., 2003), ele tem direcionamento para e ação específica no córtex das glândulas suprarrenais (é um caso de tropismo).

Importa acrescentar que ambas as denominações têm uso abonado, pois existem na língua e, assim, configuram patrimônio do idioma.

Em caso de desejo de seleção para uso formal, é útil considerar que "somos livres para falar ou escrever como quisermos, como soubermos, como pudermos. Masétambém evidente que a adequação contribui efetivamente para maior eficiência comunicativa. O uso formal, designação que sintomaticamente disputa espaço com uso ou registro culto é ainda exigência para certos e importantes momentos da vida. Quem não o domina frequentemente se defronta com limitações no acesso ao mercado de trabalho, na progressão social, na vivência escolar, na comunicação com os outros. As raras e honrosas exceções se devem a articulações mentais privilegiadas e excepcionalíssimos desempenhos profissionais, assim mesmo no âmbito da expressão falada.
Simonides Bacelar - médico, membro da Academia de Medicina de Brasília

Correspondência / Internet: simonides@uol.com.br

Na manifestação escrita da comunicação cotidiana, impõese o regime formal de tal maneira, que mesmo as lembradas exceções buscam, rápida e discretamente, o assessoramento de um professor ou professora de português para evitar, no mínimo, o anônimo, irônico e cruel castigo do anedotário" (Domício Proença Filho, doutor, professor livre docente aposentado, membro titular da Academia Brasileira de Letras, professor emérito e titular de Literatura Brasileira da Universidade Federal Fluminense em seu livro Por Dentro das Palavras da Nossa Língua Portuguesa, Rio de Janeiro, Record, 2003, p. 11-12).

\section{CORTICOIDE - CORTICOSTEROIDE}

Ambos os termos referem-se aos hormônios produzidos pelo córtex da suprarrenal, do ovário, da placenta ou similares (L. Rey, Dic de med e saúde, 2003). São sinônimos. O VOLP (2009), o Houaiss (2009), o Aurélio (2009) e o Michaelis (1998) trazem a primeira forma ao lado de corticoide.

Entretanto, corticosteroide é palavra mais bem formada para o seu significado. Literalmente, corticoide faz referência a semelhante ao córtex, casca, cortiça e corticosteroide, semelhante a ester(ol) cortical. Melhor corticosteroide que corticoide em deferência à exatidão científica e etimológica desse termo.

Não raramente, usa-se o termo esteroide nesse sentido, mas não é específico como corticosteroide.

Corticoterapia literalmente significa tratamento do córtex, diferente do que o termo indica em medicina. Para ser bom composto deveria ser corticosteroidoterapia se este nome existisse. Aqui não se discute a validade de termos no contexto idiomático normal quando se diz uma coisa e se subentende outra, mas a perfeição expressional pela qual o que se diz e escreve significa com expressa clareza ortográfica, gramatical e semântica o que se relata. Corticoesteroide é melhor termo científico por sua clareza, um dos itens básicos do estilo redacional científico. 


\section{REPRODUÇÃO ASSISTIDA, INSEMIINAÇÃO ARTIFICIAL, FECUNDAÇAO ARTIFICIAL}

São expressões presentes na linguagem médica. Frequentemente são títulos que abordam o mesmo tema em bioética. No entanto, têm acepções diversas. É necessário estudar os significados precisos de cada nome, em lugar de imaginar significações aleatoriamente, o que poderia criar entendimentos errôneos ou questionáveis. Embora haja quem determine a etimologia como um campo próprio para considerações pernósticas, de fato a etimologia mostra, frequentemente com clareza, a orientação mais precisa dos significados dos lexemas. A formação de significados por extensão, figurativos e, não raramente, opostos aos significados tradicionais e originais, é um fato da língua, mas que contribui para a ocorrência de muitos casos de desentendimentos, por ambiguidades e obscuridades, eventos que, no campo científico, pode provocar ações desastrosas e descréditos.

Define-se fecundação como ato de unir gametas para procriação. Em rigor literal, é o ato de fecundar, ou seja, tornar capaz de produzir, no caso, de procriar um ser humano. A fecundação artificial é consequência de processo técnico artificial que possibilita a união dos gametas que formam o processo da fecundação. Diz-se da mulher fecundada a que abriga os gametas já unidos, para a formação de um novo ser humano em seu seio.

Inseminação é o ato de inseminar, ou seja, introduzir o sêmen. No método artificial, usam-se meios técnicos para a introdução seminal no óvulo. A inseminação natural é feita pelo processo sexual da cópula em pessoas naturalmente férteis.

Fertilização é o ato de fertilizar, ou seja, tornar fértil, produtivo. Do latim fertilis, que produz muito. Assim, a fertilização natural humana, em rigor, se inicia no processo de sua formação corporal já no contexto embrionário e se completa na fase da puberdade. Fertilização artificial é a que se faz por métodos técnicos, já que essa fertilidade é possibilitada artificialmente em pessoas naturalmente estéreis.

Reprodução é o ato de reproduzir, ou seja, produzir outra vez. No caso, se refere à reprodução humana, ato de gerar outro ser humano. Reprodução assistida indica procedimento de reprodução, assistido por pessoas tecnicamente e profissionalmente capacitadas com uso de técnicas e instrumentos apropriados. Nesse caso, se abrangem a fertilização e a inseminação artificiais. Em medicina, o termo mais exato é reprodução artificial humana medicamente assistida. Ou, mais simplesmente, reprodução medicamente assistida.

Artificial, significa relativo a artifício, ou seja, o que é feito por meio de artifício, processo pelo qual se obtém um artefato,produto de trabalho mecânico ou objeto, dispositivo, artigo manufaturado. Do latim arte factus, feito com arte. Arte aquí tem o sentido tradicional que remonta ao platonismo, habilidade ou disposição dirigida para a execução de uma finalidade prática ou teórica, realizada de forma consciente, controlada e racional; ou que remonta ao aristotelismo, conjunto de meios e procedimentos por meio dos quais é possivel a obtenção de finalidades práticas ou a produção de objetos; aqui é sinônimo de técnica (Houaiss, 2009).

Nesse contexto, a reprodução artificial humana medicamente assistida é feita por meio de inseminação artificial que produz fecundação ovariana por métodos artificiais.

Convém buscar e estudar com rigorosidade os termos técnicos ou médicos para que não sejam erroneamente usados com o mesmo sentido, sobretudo no âmbito da comunicação e do ensino, seja dirigido a alunos, a colegas, seja a pacientes e outras pessoas interessadas por esse tema.

\section{O LDL COLESTEROL OU A LDL COLESTEROL?}

Na literatura, constam: (1) "a lipoproteína de baixa densidade" (LDL), portanto substantivo feminino; (2) "o LDL Colesterol" substantivo masculino, e (3) "a LDL Colesterol", no caso, o artigo se refere à primeira palavra que é feminina -- lipoproteína.

Ambas são formas usáveis. Se nos referirmos ao tipo de colesterol, o mais adequado é dizer o LDL-colesterol ou, ainda melhor, o colesterol-LDL com hífen, já que se refere a uma composição bioquímica .

A explicação pode ser um tanto complexa, mas eu the peço ter paciência para ler.

Quando se usam as siglas, existe tendência de aplicar questionavelmente o artigo masculino: o CT (computorized tomography), o Lilacs (Literatura LatinoAmericana e do Caribe em Ciências da Saúde), o CID (Classificação Internacional de Doenças).

LDL colesterol significa LDL cholesterol (Low-density lipoprotein cholesterol) . Em português se diz colesterol LDL ou colesterol lipoproteína de baixa densidade ou "colesterol ruim" ou "colesterol mau".

Entretanto, sabemos que colesterol, é um álcool secundário; do grego cholé, bile, e esterol, um esteroide com função de álcool (Houaiss, 2009). As células do organismo recebem o colesterol transportado por lipoproteínas de baixa ou muito baixa densidade (Luis Rey, Dic. de Termos Técnicos de Med. e Saúde, 2003). Assim, se forma uma composição complexa lipoproteica 
com colesterol, que poderíamos chamar de complexo colesterol-lipoproteico de baixa densidade, expressão presente na literatura. A sigla normativa seria CLBD, usada em textos castelhanos (colesterol de lipoproteínas de baja densidad). Em inglês, low density lipoprotein cholesterol, cuja sigla normativa é LDLC, existente na literatura anglo-americana, como se vê na web.

Assim, a forma "a LDL-colesterol" é questionável por seu hibridismo inglês-português ou anglo-português. A forma o LDL-colesterol é mais apropriada, apesar do hibridismo, se considerarmos a sigla LDL como prefixo agregado a colesterol, tipo de composição muito usada em nomenclatura bioquímica: pHmetria, PUVAterapia, TSHoma, Rh-positivo e outros casos encontrados na literatura. Como siglas e afixos são configurações diferentes, o uso de hífen é recomendável: $\mathrm{pH}$-metria, LDL-colesterol, PUVA-terapia e existem na literatura.

Dizer o LDL-colesterol ou o colesterol-LDL é mais adequado, assim como dizemos a pH-metria, a PUVAterapia (de psoraleno-raios ultravioleta) e o TSH-oma (tumor produtor de tireotropina). No caso, a referência é ao tipo de colesterol. A forma o colesterol LDL está mais presente na literatura dezenas de milhares de vezes, como podemos verificar na web.

Não é errado dizer a LDL colesterol se nos referirmos especificamente ao tipo de lipoproteína conjugada ao colesterol. Mas, se quisermos evitar questionamentos, sempre que nos referirmos ao tipo de colesterol, é mais vantajoso usar o colesterol-LDL. Com hífen.

\section{CORPO PINEAL OU GLÂNDULA PINEAL?}

Pineal significa relativo a pinha ou que tem forma de pinha. Do latim pinea, pinha, fruto do pinheiro, pinus em latim (Houaiss, 2009; A. Ferreira, dic lat port, 1996).

Em termos formais, indica-se o termo completo e exato glândula pineal, em lugar de apenas o adjetivo pineal. Também é conhecida por outros nomes, como epífise do cérebro, corpo pineal, órgão pineal, conário.

A Terminologia Anatômica traz em latim corpus pineale e glandula pinealis. 0 termo glândula pineal é a denominação que consta desta obra, tradução do latim glandula pinealis, com a observação de que é o preferido por ter função endócrina estabelecida sem dúvidas (Sociedade Brasileira de Anatomia, Terminologia Anatômica, 2001).

Pineal, provavelmente tem influência do francês pinéale, nome usado em termos como glande pinéale ou corps pinéale, nomes antigos, desde 1503, para designar epífise (Houaiss, ob. cit.). De fato, ainda se encontra na literatura a expressão epífise neural.
Texto interessante: a glândula pineal, epífise neural ou pineal é uma glândula endócrina mínima, que tem formato de pinha, fruto do pinheiro, ou de um grão, situada próxima ao centro do cérebro entre os dois hemisférios. Ela tem cerca de cinco milímetros de diâmetro.

Há controvérsias sobre as tarefas que cabem a esta glândula, pois muitos estudiosos creem que ela não detém atualmente nenhuma função específica, ou seja, seria simplesmente o que se conhece como órgão vestigial. Mas algumas certezas parecem existir, como a de sua contribuição no equilíbrio dos ciclos considerados vitais, especialmente o do sono, e na regulação dos esforços sexuais e reprodutivos.

Essa glândula é considerada muito útil. A ciência descobriu recentemente que ela é um pequeno tecido vermelho-acinzentado, responsável pelo aprimoramento e pelas mudanças progressivas nos órgãos sexuais. Quando já não é mais útil nessa tarefa, vai aos poucos se convertendo em uma massa celular fibrosa, incapaz de produzir hormônios. Ela é constantemente avistada em exames radiográficos do crânio, pois é intensamente calcificada. Algumas experiências realizadas com roedores indicam que essa glândula pode exercer profunda influência sobre o desempenho de drogas, como a cocaína, e de antidepressivos, especialmente a fluoxetina, no organismo.

O filósofo René Descartes defendia a tese de que a glândula pineal seria a morada da alma. No Oriente, acredita-se que ela é uma espécie de terceiro olho atrofiado. Os praticantes da ioga indiana afirmam que ela é a janela de Brahma, conhecida como o Olho de Diamante, que uma vez adequadamente treinado poderia perceber uma realidade transcendental. Lobsang Rampa, pseudônimo adotado por um escritor inglês, também se devotava ao conhecimento deste elemento do organismo.

Alguns vêem na pineal uma espécie de antena poderosa, teoria esta estimulada pela presença de cristais de apatita neste órgão, os quais vibrariam de acordo com as ondas eletromagnéticas por eles atraídas. No ser humano, essa glândula estaria em conexão direta com outras regiões do cérebro, tais como o córtex cerebral, que teria a capacidade de traduzir as mensagens transmitidas por ela. Assim, seria possivel explicar eventos considerados paranormais, como clarividência, telepatia e mediunidade.

A doutrina espírita, elaborada por Allan Kardec no século XIX, também se empenha em encontrar justificativas para a atuação da glândula pineal. Segundo a teoria espírita, a epífise é considerada a glândula responsável pela existência da vida no plano espiritual e mental, além 
de deter um intenso significado no corpo etéreo. Ela comanda as emoções, pois tem acesso irrestrito a todo o sistema endócrino, atuando principalmente na esfera sexual. A pineal também seria capaz de dirigir as forças do inconsciente apenas com o poder da vontade. Hoje este tema é amplamente investigado pelo psiquiatra brasileiro Sérgio Felipe de Oliveira, especialista em psicobiofísica.

Do ponto de vista hindu, a glândula pineal é órgão essencial ao organismo humano, detentor de dois chacras ou centros energéticos muito importantes - o do terceiro olho, localizado na região central da fronte, e o coronário, também situado no campo encefálico.

\section{FONTES}

http://pt.wikipedia.org/wiki/Glândula_pineal http://www.esoterikha.com/saude/saude-glandula-pineal.php http://pt.wikipedia.org/wiki/Sérgio_Felipe_de_Oliveira 